\title{
Results of radiofrequency ablation in children with tachycardia-induced cardiomyopathy
}

\author{
Hayrettin Hakan Aykan, Tevfik Karagöz, Alper Akın, Ahmet İdem, Sema Özer, Alpay Çeliker ${ }^{1}$
}

Department of Pediatric Cardiology, Faculty of Medicine, İhsan Doğramacı Childrens Hospital, Hacettepe University; Ankara-Turkey ${ }^{1}$ Department of Pediatric Cardiology, Faculty of Medicine, Acıbadem University; İstanbul-Turkey

ABSTRACT

Objective: Tachycardia-induced cardiomyopathy (TIC) is a rare but potentially curable cause of dilated cardiomyopathy. Data on radiofrequency ablation (RFA) for TIC is limited. The aim of this study is to present our experience with RFA in children with TIC, retrospectively.

Methods: The medical records of patients with TIC and those underwent RFA between 2000-2011 were systematically reviewed. Demographics and echocardiographic features were recorded. Tachycardia-induced cardiomyopathy is defined as dilatation of the heart chambers or heart failure with chronic or very frequent cardiac arrhythmia. Diagnosis was confirmed with normalization of functions after sinus rhythm has been achieved.

Results: A total of 12 patients with a mean age of $6.3 \pm 4.1$ years (in utero-11.5 years) at diagnosis were enrolled in the study consisting of 7 patients with permanent junctional reciprocating tachycardia and 5 patients with focal atrial tachycardia. The mean pre-RFA left ventricular end-diastolic diameter and left ventricular ejection fraction (LVEF) values were $49.1 \pm 9.6 \mathrm{~mm}(32-66)$ and $40.8 \pm 13.4 \%(23-57 \%)$, respectively. One month after RFA, the mean LVEF value was $62 \pm 4.9 \%$ (52-69), with only 2 out of 12 patients' LVEF values were still lower than $58 \%$. Tachycardia recurrence was observed in 4 patients, 3 of which had successful repeated RFA procedure. Overall, cure for arrhythmia was achieved in 11 patients (92\%), while reversal of heart failure achieved in all patients. In 1 patient permanent complete AV block was developed after the procedure.

Conclusion: Treatment of tachycardia with RFA, particularly in patients with arrhythmia refractory to medical therapy, is a feasible and effective treatment option regardless of age. (Anadolu Kardiyol Derg 2014; 14: 625-30)

Key words: radiofrequency cathater ablation, tachycardia, cardiomyopathy, child

\section{Introduction}

The cardiomyopathies are a heterogenous group of disorders that are characterized by structural and/or functional deterioration in heart muscle tissue in the absence of ischemic heart disease or any signs of abnormal overload. Long standing, persistent tachycardia is a well-established cause of non-ischemic cardiomyopathy and heart failure, which is also known as tachycardia-induced cardiomyopathy (TIC). The first case of TIC was described by Gossage and Braxton Hicks (1) in a young individual with atrial fibrillation who had unexplained left ventricular dysfunction and heart failure. Subsequently, Whipple et al. (2) described the first experimental case of TIC in 1962.

Tachycardia-induced cardiomyopathy, which results in a clinical feature of heart failure, is characterized by the development of ventricular systolic and/or diastolic dysfunction and ventricular dilatation in the presence of rapid and/or irregular ventricular rhythm, all of which is partially or completely resolve following normalization of heart rate (3-5). The reversibility of symptoms and cardiac functions in patients with TIC highlights the need for pursuit of an aggressive treatment approach. The aim of treatment should be to achieve normal sinus rhythm by antiarrhythmic medication initially and then by means of curative ablation therapy, if unsuccessful. Ablation of the atrioventricular junction with implantation of a permanent pacemaker is considered as the last option (6). Currently, although ablative modalities have been proven to be safe and effective in the management of arrhythmias refractory to medical treatment, data on the efficacy of radiofrequency ablation (RFA) in children with TIC is limited. The aim of this study is to share our experience on RFA in children with TIC.

Address for Correspondence: Dr. H. Hakan Aykan, Hacettepe Üniversitesi Tıp Fakültesi, İhsan Doğramacı Çocuk Hastanesi, Pediyatrik Kardiyoloji Bölümü, 06100, Samanpazarı, Ankara-Türkiye

Phone: +90 3123051157 Fax: +90 3123090220 E-mail: h_h_aykan@yahoo.com

Accepted Date: 17.01.2014 Available Online Date: 08.04.2014 


\section{Methods}

This single centre study was undertaken in Pediatric Cardiology Department of Hacettepe University Faculty of Medicine, İhsan Doğramacı Children's Hospital. The study protocol was approved by the locally appointed Ethics Committee. A written informed consent was obtained from the patients or parents before the procedure. The medical records of patients with TIC who were managed in our clinic between 2000 and 2011 were reviewed retrospectively and those who underwent subsequent RFA were identified. Demographics and clinical characteristics of the patients, details of the RFA procedures and their complications, as well as post-RFA follow-up data were extracted. Tachycardia-induced cardiomyopathy is defined as dilatation of the heart chambers or presence of heart failure with coexisting chronic or very frequent cardiac arrhythmia (incessant supraventricular tachycardia, incessant ventricular tachycardia) according to Fenelon et al. (7). Chronic tachycardia that occurs in $10-15 \%$ of the day is considered as incessant tachycardia. The diagnosis was confirmed with the normalization of systolic function after normal sinus rhythm has been achieved.

\section{Results}

A total of 12 patients ( 6 male and 6 female) with TIC who underwent RFA were included in the study. The mean age at diagnosis was $6.3 \pm 4.1$ years (in utero- 11.5 years) and mean age at appeal to our clinic was $7.8 \pm 4.8$ years ( 15 months- 16.5 years). Mean age and mean weight at the time of RFA procedure were $8.9 \pm 5.7$ years ( 15 months- 17.5 years) and $27.6 \pm 16.2 \mathrm{~kg}(10-60 \mathrm{~kg})$, respectively. While 7 of the patients had permanent junctional reciprocating tachycardia (PJRT), the other 5 patients had focal atrial tachycardia (FAT). The demographic and clinical characteristics of the study population have been summarized in Table 1.

Patient 6 and 9 with PJRT had been diagnosed with myocarditis prior to referral to our clinic and patient 9 had received corticosteroid and intravenous immunoglobulin (IVIG) medications.

Radiofrequency ablation procedures were performed after failure of antiarrhythmic medications was recognized. The mean procedure, fluoroscopy and radiofrequency energy exposure durations were $104 \pm 39$ minutes (45-195), $24 \pm 10$ minutes (12-38) and $191 \pm 90$ seconds (30-350), respectively. Mean follow-up period was $4.8 \pm 3.2$ years $(1-10)$. Mean values for pre-RFA left ventricular end-diastolic diameter (LVEDD) and left ventricular ejection fraction (LVEF) were $49.1 \pm 9.6 \mathrm{~mm}$ and $40.8 \pm 13.4 \%$ (23$57 \%$ ), respectively. One month after the initial RFA procedures, only 2 patients (patients 4 and 12) had persisting low LVEF values of lower than \%58. Both of these patients had undergone repeated RFA procedure due to recurrence of tachycardia and LVEF values showed significant improvement at the first month during follow-up. With regard to the 7 patients who had PJRT, mean pre-procedural LVEF value was $36 \pm 13.3 \%(23-57 \%)$ compared with the mean LVEF value of $64 \pm 2.6 \%(61-69 \%) 1$ month after the procedure. Changes in the pre- and post-procedural LVEF values are depicted in Figure 1.

Recurrence of tachycardia observed in 4 patients within 6 months after the RFA procedure. One of these patients was a 15-month-old (patient 10) whose systolic functions did not deteriorate despite the recurrence. Second RFA or electrophysiologic study was not considered necessary since the arrhythmia could be kept under control by medical treatment. Re-ablation, which was performed in the remaining 3 patients for recurrence, was successful with the abolishment of the arrhythmia. While

Table 1. General characteristics of patients with tachycardia induced cardiomyopathy

\begin{tabular}{|c|c|c|c|c|c|c|c|c|c|c|c|c|c|c|c|c|c|}
\hline Patient & $\begin{array}{c}\text { Age at } \\
\text { diagnosis }\end{array}$ & $\begin{array}{l}\text { RFA } \\
\text { age }\end{array}$ & \begin{tabular}{|c|} 
RFA \\
weight, \\
kg
\end{tabular} & $\begin{array}{c}\text { Gen- } \\
\text { der }\end{array}$ & $\begin{array}{l}\text { Diag- } \\
\text { nosis }\end{array}$ & $\begin{array}{c}\text { Ablation } \\
\text { site }\end{array}$ & $\begin{array}{c}\text { Procedure } \\
\text { duration, } \\
\text { minute }\end{array}$ & $\begin{array}{c}\text { Flouroscopy } \\
\text { duration, } \\
\text { minute }\end{array}$ & $\begin{array}{c}\text { RF } \\
\text { energy } \\
\text { duration, } \\
\text { second }\end{array}$ & $\begin{array}{c}\text { Follow- } \\
\text { up } \\
\text { period, } \\
\text { year }\end{array}$ & $\begin{array}{c}\text { Initial } \\
\text { LVEDD, } \\
\text { (mm) }\end{array}$ & $\begin{array}{c}\text { Initial } \\
\text { LVEF, } \\
\%\end{array}$ & $\begin{array}{c}1 . \\
\text { month } \\
\text { LVEF, } \\
\%\end{array}$ & $\begin{array}{c}\text { Last } \\
\text { LVEF, } \\
\%\end{array}$ & $\begin{array}{c}\text { Re- } \\
\text { current } \\
\text { Tac- } \\
\text { hycardia }\end{array}$ & $\begin{array}{c}\text { Re- } \\
\text { abla- } \\
\text { tion }\end{array}$ & $\begin{array}{c}\text { Re- } \\
\text { current } \\
\text { TIC }\end{array}$ \\
\hline 1 & $11 y$ & $14 y$ & 45 & $\mathrm{~F}$ & FAT & RA-CT & 70 & 18 & 240 & 4 & 44 & 55 & 67 & 66 & No & No & No \\
\hline 2 & $5 y$ & $5.5 y$ & 17 & $F$ & PJRT & RA-PS & 75 & 25 & 240 & 9 & 48 & 44 & 65 & 66 & Yes & Yes & No \\
\hline 3 & $6 y$ & $6 y$ & 18 & $\mathrm{~F}$ & PJRT & RA-PS & 120 & 36 & 300 & 4 & 46 & 57 & 63 & 63 & No & No & No \\
\hline 4 & $11 y$ & 11.5y & 36 & $\mathrm{M}$ & FAT & RA-FO & 120 & 33 & 200 & 7 & 50 & 54 & 56 & 67 & Yes & Yes & No \\
\hline 5 & $2.5 y$ & $2.7 y$ & 14 & $\mathrm{M}$ & PJRT & RA-CSO & 130 & 38 & 350 & 3 & 48 & 34 & 61 & 70 & No & No & No \\
\hline 6 & $3 y$ & $3.6 y$ & 12 & $M$ & PJRT & RA-CSO & 80 & 15 & 120 & 2.5 & 38 & 46 & 63 & 69 & No & No & No \\
\hline 7 & In utero & $3.5 y$ & 13 & $M$ & PJRT & RA-CSO & 75 & 13 & 30 & 10 & 53 & 24 & 65 & 68 & No & No & No \\
\hline 8 & $13 y$ & $13 y$ & 48 & $M$ & FAT & RA-CT & 45 & 17 & 240 & 1 & 58 & 47 & 65 & 74 & No & No & No \\
\hline 9 & $11 y$ & $15 y$ & 60 & $F$ & PJRT & RA-CSO & 120 & 20 & 100 & 10 & 49 & 23 & 69 & 67 & No & No & No \\
\hline 10 & $9 m$ & $15 \mathrm{~m}$ & 10 & $\mathrm{~F}$ & FAT & LA-PVO & 120 & 12 & 150 & 2 & 32 & 56 & 58 & 62 & Yes & No & No \\
\hline 11 & $6 y$ & $17.5 y$ & 45 & $\mathrm{M}$ & PJRT & RA-CSO & 100 & 36 & 120 & 4.5 & 64 & 24 & 62 & 70 & No & No & No \\
\hline 12 & $11.5 y$ & $12.2 y$ & 34 & $\mathrm{~F}$ & FAT & LA-PVO & 195 & 35 & 210 & 1.5 & 54 & 28 & 52 & 71 & Yes & Yes & No \\
\hline
\end{tabular}




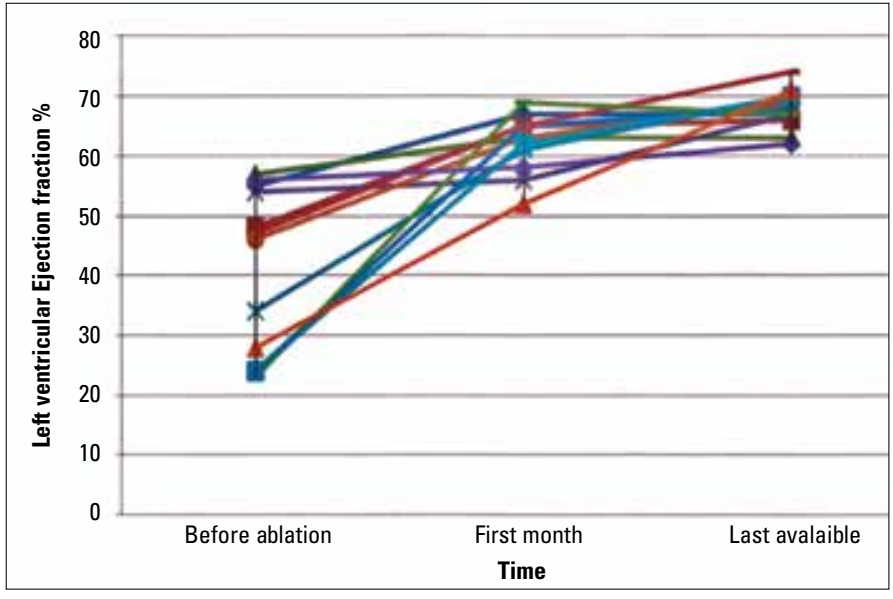

Figure 1. Left ventricular ejection fraction values before and after ablation of arrhythmic focus

the diagnosis of arrhythmia remained unchanged in patients 2 and 12 with recurrence, it was changed as atrio-ventricular reentrant tachycardia in patient 4.

Patient 7 was our first patient who underwent RFA at 3.5 years old with PJRT. The procedure was complicated by permanent complete AV block which necessitated implantation of a pacemaker. This patient was diagnosed during intrauterine period and had a pre-RFA LVEF of $24 \%$. With the implantation of pacemaker, the patient's ventricular functions returned to normal.

\section{Discussion}

In this study revealed that, treatment of tachycardia-induced cardiomyopathy with RFA is a feasible and effective treatment.

The exact prevalence of TIC remains unknown. Reports in the literature in pediatric age groups are limited to case reports or small case series (8-12). The main reason behind this is the diagnostic challenge associated with TIC, particularly in the presence of both dilated cardiomyopathy and arrhythmia which makes it difficult to determine which developed first; a classic "Chicken and the Egg" dilemma. As in some cases in our study, some patients with TIC may receive treatment for misdiagnoses of myocarditis or dilated cardiomyopathy related to other causes. In two small studies, it was postulated that the only distinctive factor between TIC and dilated cardiomyopathy is that TIC patients tend to have lower $\operatorname{LVEDD}(13,14)$. However, the most striking difference between two conditions is the recovery of left ventricular function following eradication of the tachyarrhythmia in TIC patients, which highlights the importance of pursuing an aggressive strategy to keep the arrhythmia under control. Although recurrence of tachycardia occurred in some of our patients, significant improvements in left ventricular function were observed during the arrhythmia-free periods which helps to confirm the diagnosis of TIC.

The clinical presentation of TIC is similar to other forms of cardiomyopathies. Because of faster ventricular rates and their inability to verbalize their symptoms, infants usually show typical heart failure symptoms (respiratory distress, diaphoresis, and poor feeding) earlier. On the other hand, older children may present with palpitation, exercise intolerance, chest pain or syncope (15). As the underlying tachyarrhythmia may not be apparent, a high index of suspicion is the most important step for diagnosis of TIC. Therefore, an electrocardiogram (ECG) and Holter ECG monitorization should be performed and evaluated carefully on any patient presenting with new onset dilated cardiomyopathy. While the responsible tachyarrhythmia may be observed, other abnormal findings also may be seen even if the child has a slower rate during the electrocardiogram. Infectious, familial, metabolic, mitochondrial, toxic, inflammatory, and neuromuscular processes should be considered in the differential diagnosis. Although most cases remain idiopathic, genetic and metabolic etiologies such as storage disorders, mitochondrial disorders, and carnitine deficiency should also be considered in infants and young children with new onset cardiomyopathy.

In our study, 7 patients had PJRT (58.3\%) and 5 had FAT $(41.6 \%)$, both of which arrhythmias most frequently are associated with TIC. Other implicated arrhythmias are atrial fibrillation, atrial flutter, atrioventricular nodal reentrant tachycardia, ventricular tachycardia and frequent ventricular premature beats (16-19).

PJRT is an orthodromic tachycardia which develops as a result of anterograde conduction over the atrioventricular node followed by slow decremental retrograde conduction via an accessory pathway usually located in the posteroseptal region (20). It is characterized by episodes of narrow QRS complex tachycardia alternating with brief periods of sinus rhythm. During sinus rhythm, the surface electrocardiogram (ECG) is normal. During tachycardia, negative $P$ waves are typically present in leads II, III and aVF and usually in V4 to V6, with a long RP interval (21). It is a relatively uncommon arrhythmia which usually follows a persistent course. It generally occurs in children but may remain undiagnosed well into adulthood, thus potentially leading to TIC $(11,22)$. Permanent junctional reciprocating tachycardia of infancy is less likely to resolve spontaneously in comparison to other atrioventricular re-entry tachycardias (16). Permanent junctional reciprocating tachycardia is also frequently refractory to medical therapy, although favorable results have been reported with transcatheter RFA. In a retrospective multicentric study by Vaksmann et al. (11) on 85 patients with PJRT aged between 4-25 years, 18 patients underwent a total of 24 RFA procedures with a success rate of $50 \%$ in children under the age of 10 years compared to a success rate of $83 \%$ in older children. In our study 5 of the 7 patients with PJRT were younger than 10 years of age and RFA was successful in all 5 patients. But in 1 of 5 patients, recurrence was observed during follow-up and eradicated with a second ablation procedure. In the other two patients who were older than 10 years, RFA was successful with no recurrence.

Focal atrial tachycardias are a broad group of supraventricular tachycardias that are characterized by a rapid rhythm arising from structures above the bundle branches, including the atrium. 
They mostly develop after surgery for congenital heart disease, although spontaneous cases have been reported during intrauterine period as well as in children and adolescents. Incessant FAT is an infrequent cause of TIC, accounting for $5 \%$ of adult cases and $14 \%$ of pediatric cases (23). It results in myocardial dysfunction in approximately $10 \%$ of affected individuals, with children more likely to present with TIC than adults (24). In FAT, ECG demonstrates an inappropriately rapid heart rate for age and narrow QRS complex. The $P$ wave morphology can appear normal or abnormal, depending upon the site of origin of the tachycardia. The atrial rate during FAT is generally between 130 and 250 beats per minute but infants often have faster rates. Monitoring with serial ECGs is invaluable for distinguishing FAT from sinus tachycardia. Although focal ATs are regular, "warm up" and "cool down" patern in tachycardia and an abrupt onset or termination favors a FAT.

Infants and small children with FAT tend to respond well to medical therapy, with the likelihood of spontaneous resolution later in life $(25,26)$. In a previous study, a spontaneous resolution rate within 1 year of $93 \%$ was observed in 15 infants less than 6 months of age (25), whereas in another study lower resolution rates with a poorer response to medical treatment was reported in children older than 3 years of age (26). In our study, 4 of the 5 patients with FAT who underwent ablation therapy were older than 3 years of age. $0 \mathrm{n}$ the other hand, recurrence of tachycardia occurred in 3 of the 5 patients with FAT after the initial RFA procedure, one of whom was a 15-month-old whose systolic functions improved during follow-up. This patient responded well to antiarrhythmic medication and did not require reablation. In the other 2 patients with recurrence, cure was achieved by re-ablation. Although the recurrence rate after the initial RFA procedures in our study seems to be high, cure has been achieved with reablation in most patients. Higher early recurrence rates may be attributed to the learning curve.

In a study of catheter ablation in children, the overall complication rate was $7.2 \%$, with a major complication rate of $2.6 \%$. The most frequently reported complications are second and third degree AV blocks, perforation, pericardial effusion, embolization, brachial plexus injury, and pneumothorax (27). Also, in rare cases coronary artery injuries were reported during or after ablation procedure $(28,29)$. In a report by Smith et al. $(30)$ published in 1986, ablation was successful in eradicating tachycardia in 5 patient with PJRT, however AV block requiring placement of a pacemaker developed in 4 patients. Through the years improvement in the success rates of ablation therapy has been accompanied by a decreased of procedure-related complications $(11,22,31,32)$.

In our study, only 1 patient (3.5 years old) with PJRT had experienced permanent complete AV block after RFA. This is the only major complication observed in our study and ventricular functions of the patient returned to normal after permanent pacemaker implantation. Nevertheless, nodal ablation and placement of a permanent pacemaker is the recommended treatment of choice in patients where ablation had failed (6).
Persistently rapid or irregular ventricular rates trigger a sequence of events starting with dilatation of the heart chambers and mitral regurgitation which eventually lead to elevation in end-diastolic pressures with reduction in EF and ultimately symptomatic heart failure. Several experimental models have demonstrated significant reduction in systemic arterial pressure and cardiac output in animals with 24 hours of sustained rapid pacing $(3,33)$. Despite many neurohumoral and cellular activation mechanisms have been postulated, the exact mechanisms that produce these changes are not well understood. Studies in animal models have shown that persistent tachycardia depletes high-energy stores as evidenced by reduced myocardial levels of creatine, phosphocreatine, and adenosine triphosphate (ATP), and diminished activity of the Na-K-ATPase pump $(34,35)$. These changes are probably due to alterations in cellular metabolism with mitochondrial injury and increased activity of Krebs cycle oxidative enzymes. Depletion of high-energy stores, which may be mediated in part by ischemia, is reversible and may explain the reversibility of the developed cardiomyopathy (36). Abnormalities in both calcium channel activity and sarcoplasmic reticulum calcium transport may contribute to the myocardial dysfunction in TIC $(36,37)$. Diminished beta-adrenergic responsiveness and beta-1 receptor down-regulation has also been described in TIC patients (38).

Tachycardia-induced cardiomyopathy is considered as a potentially reversible condition, since many studies have shown normalization of LVEF and complete resolution of symptoms following sufficient ventricular rate control. Improvement is often dramatic, usually beginning within the first few weeks, continuing gradually up to 6 months $(39,40)$. Recovery is faster in younger children (9) The lack of improvement in ventricular functions should not rule out TIC but rather indicate an advanced and irreversible stage of disease because once a threshold is passed to an advanced disease, deteriorated ventricular functions may not improve (41).

Our findings are consistent with those in the current literature in that a dramatic improvement in systolic function was observed following ablation therapy, with LVEF increasing to more than $50 \%$ in all patients at the first month on follow-up. Furthermore by the end of the study period, LVEF values returned to normal range in all patients. In our study RFA was successful in 11 out of 12 patients with TIC (92\%), while significant clinical and echocardiographic improvements with resolution of heart failure were observed in all patients. Only 1 patient whose tachycardia was eradicated by RFA developed permanent AV-block after the procedure requiring implantation of a permanent pacemaker.

\section{Conclusion}

Although RFA is a well-established method for treatment of arrhythmias in older individuals, it is also an effective method that could be used for the management of children with left ventricular dysfunction due to tachycardia refractory to medical therapy regardless of age. 


\section{Conflict of interest: None declared.}

Peer-review: Externally peer-reviewed.

Authorship contributions: Concept - T.K., H.H.A., A.A.; Design - A.A., A.I.; Supervision - T.K., H.H.A., A.Ç.; Data collection \&/or processing - T.K., H.H.A., S.Ö., A.Ç.; Analysis \&/or interpretation - A.A., A.I., S.Ö.; Literature search - A.A., S.Ö., A.l.; Writing H.H.A., T.K.; Critical review - H.H.A., T.K., A.A.

\section{References}

1. Gossage AM, Braxton Hicks JA. On auricular fibrillation. OJM 1913; 6: 435-40.

2. Whipple GH, Sheffield LT, Woodman EG, Teophilis C, Friedman S. Reversible congestive heart failure due to chronic rapid stimulation of the normal heart. Proc N Engl Cardiovasc Soc 1962; 20: 39-40.

3. Shinbane JS, Wood MA, Jensen DN, Ellenbogen KA, Fitzpatrick AP, Scheinman MM. Tachycardia-induced cardiomyopathy: a review of animal models and clinical studies. J Am Coll Cardiol 1997; 29: 709-15. [Crossref]

4. Packer DL, Bardy GH, Worley SJ, Smith MS, Cobb FR, Coleman $\mathrm{RE}$, et al. Tachycardia-induced cardiomyopathy: a reversible form of left ventricular dysfunction. Am J Cardiol 1986; 57: 56370. [Crossref]

5. Umana E, Solares CA, Alpert MA. Tachycardia-induced cardiomyopathy. Am J Med 2003; 114: 51-5. [Crossref]

6. Houmsse M, Tyler J, Kalbfleisch S. Supraventricular tachycardia causing heart failure. Curr Opin Cardiol 2011; 26: 261-9. [Crossref]

7. Fenelon G, Wijns W, Andries E, Brugada P. Tachycardiomyopathy: mechanisms and clinical implications. Pacing Clin Electrophysiol 1996; 19: 95-106. [Crossref]

8. Semizel E, Ayabakan C, Ceviz N, Çeliker A. Permanent form of junctional reciprocating tachycardia and tachycardia-induced cardiomyopathy treated by catheter ablation: a case report. Turk $\mathrm{J}$ Pediatr 2003; 45: 338-41.

9. De Giovanni JV, Dindar A, Griffith MJ, Edgar RA, Silove ED, Stumper 0 , et al. Recovery pattern of left ventricular dysfunction following radiofrequency ablation of incessant supraventricular tachycardia in infants and children. Heart 1998; 79: 588-92.

10. Arya A, Haghjoo M, Davari P, Sadr-Ameli MA. Resolution of tachycardia-induced cardiomyopathy following ablation of verapamilsensitive idiopathic left ventricular tachycardia. Pediatr Cardiol 2006; 27: 146-8. [Crossref]

11. Vaksmann G, D'Hoinne C, Lucet V, Guillaumont S, Lupoglazoff JM, Chantepie $A$, et al. Permanent junctional reciprocating tachycardia in children: a multicentre study on clinical profile and outcome. Heart 2006; 92: 101-4. [Crossref]

12. Qi JG, Xing CQ, Liu XQ, Zhang QY, Chen YH, Du JB. Clinical characteristics and follow-up study of tachycardia-induced cardiomyopathy in 12 children. Zhonghua Er Ke Za Zhi 2011; 49: 933-8.

13. Jeong YH, Choi KJ, Song JM, Hwang ES, Park KM, Nam GB, et al. Diagnostic approach and treatment strategy in tachycardiainduced cardiomyopathy. Clin Cardiol 2008; 31: 172-8. [Crossref]

14. Fujino T, Yamashita T, Suzuki S, Sugiyma H, Sagara K, Sawada H, et al. Characteristics of congestive heart failure accompanied by atrial fibrillation with special reference to tachycardia-induced cardiomyopathy. Circ J 2007; 71: 936-40. [Crossref]
15. Macicek SM, Macias CG, Jefferies JL, Kim JJ, Price JF. Acute heart failure syndromes in the pediatric emergency department. Pediatrics 2009; 124: e898-904. [Crossref]

16. Chiladakis JA, Vassilikos VP, Maounis TN, Cokkinos DV, Manolis AS. Successful radiofrequency catheter ablation of automatic atrial tachycardia with regression of the cardiomyopathy picture. Pacing Clin Electrophysiol 1997; 20: 953-9. [Crossref]

17. Gillette PC, Smith RT, Garson A Jr, Mullins CE, Gutgesell HP, Goh TH, et al. Chronic supraventricular tachycardia. A curable cause of congestive cardiomyopathy. JAMA 1985; 253: 391-2. [Crossref]

18. Aguinaga L, Primo J, Anguera I, Mont L, Valentino M, Brugada J, et al. Long-term follow-up in patients with the permanent form of junctional reciprocating tachycardia treated with radiofrequency ablation. Pacing Clin Electrophysiol 1998; 21: 2073-8. [Crossref]

19. Yarlagadda RK, Iwai S, Stein KM, Markowitz SM, Shah BK, Cheung JW, et al. Reversal of cardiomyopathy in patients with repetitive monomorphic ventricular ectopy originating from the right ventricular outflow tract. Circulation 2005; 112: 1092-7. [Crossref]

20. Critelli G, Gallagher JJ, Monda V, Coltorti F, Scherillo M, Rossi L. Anatomic and electrophysiologic substrate of the permanent form of junctional reciprocating tachycardia. J Am Coll Cardiol 1984; 4: 601-10. [Crossref]

21. Gaita F, Haissaguerre M, Giustetto C, Fischer B, Riccardi R, Richiardi $\mathrm{E}$, et al. Catheter ablation of permanent junctional reciprocating tachycardia with radiofrequency current. J Am Coll Cardiol 1995; 25: 648-54. [Crossref]

22. Lindinger $A$, Heisel $A$, von Bernuth $G$, Paul T, Ulmer $H$, Kienast $W$, et al. Permanent junctional re-entry tachycardia. A multicentre longterm follow-up study in infants, children and young adults. Eur Heart J 1998; 19: 936-42. [Crossref]

23. Ko JK, Deal BJ, Strasburger JF, Benson DW Jr. Supraventricular tachycardia mechanisms and their age distribution in pediatric patients. Am J Cardiol 1992; 69: 1028-32. [Crossref]

24. Medi C, Kalman JM, Haqqani H, Vohra JK, Morton JB, Sparks PB, et al. Tachycardia-mediated cardiomyopathy secondary to focal atrial tachycardia: long-term outcome after catheter ablation. J Am Coll Cardiol 2009; 53: 1791-7. [Crossref]

25. Bauersfeld U, Gow RM, Hamilton RM, Izukawa T. Treatment of atrial ectopic tachycardia in infants $<6$ months old. Am Heart $\mathrm{J}$ 1995; 129: 1145-8. [Crossref]

26. Salerno JC, Kertesz NJ, Friedman RA, Fenrich AL Jr. Clinical course of atrial ectopic tachycardia is age-dependent: results and treatment in children $<3$ or $>$ or $=3$ years of age. J Am Coll Cardiol 2004; 43: 438-44. [Crossref]

27. Friedman RA, Walsh EP, Silka MJ, Calkins $H$, Stevenson WG, Rhodes LA, et al. NASPE Expert Consensus Conference: Radiofrequency catheter ablation in children with and without congenital heart disease. Report of the writing committee. North American Society of Pacing and Electrophysiology. Pacing Clin Electrophysiol 2002; 25: 1000-17. [Crossref]

28. Schneider HE, Kriebel T, Gravenhorst VD, Paul T. Incidence of coronary artery injury immediately after catheter ablation for supraventricular tachycardias in infants and children. Heart Rhythm 2009; 6: 461-7. [Crossref]

29. Bertram H, Bokenkamp R, Peuster M, Hausdorf G, Paul T. Coronary artery stenosis after radiofrequency catheter ablation of accessory atrioventricular pathways in children with Ebstein's malformation. Circulation 2001; 103: 538-43. [Crossref]

30. Smith RT Jr, Gillette PC, Massumi A, McVey P, Garson A Jr. Transcatheter ablative techniques for treatment of the permanent 
form of junctional reciprocating tachycardia in young patients. $J$ Am Coll Cardiol 1986; 8: 385-90. [Crossref]

31. Kim YH, Park HS, Hyun MC, Kim YN. Pediatric tachyarrhythmia and radiofrequency catheter ablation: results from 1993 to 2011. Korean Circ J 2012; 42: 735-40. [Crossref]

32. Joung B, Lee M, Sung JH, Kim JY, Ahn S, Kim S. Pediatric radiofrequency catheter ablation: sedation methods and success, complication and recurrence rates. Circ J 2006; 70: 278-84. [Crossref]

33. Wilson JR, Douglas P, Hickey WF, Lanoce V, Ferraro N, Muhammad $A$, et al. Experimental congestive heart failure produced by rapid ventricular pacing in the dog: cardiac effects. Circulation 1987; 75 : 857-67. [Crossref]

34. Moe GW, Montgomery C, Howard RJ, Grima EA, Armstrong PW. Left ventricular myocardial blood flow, metabolism, and effects of treatment with enalapril: further insights into the mechanisms of canine experimental pacing-induced heart failure. J Lab Clin Med 1993; 121: 294-301.

35. Spinale FG, Clayton C, Tanaka R, Fulbright BM, Mukherjee R, Schulte $\mathrm{BA}$, et al. Myocardial $\mathrm{Na}+, \mathrm{K}(+)$-ATPase in tachycardia induced cardiomyopathy. J Mol Cell Cardiol 1992; 24: 277-94. [Crossref]
36. O'Brien PJ, lanuzzo CD, Moe GW, Stopps TP, Armstrong PW. Rapid ventricular pacing of dogs to heart failure: biochemical and physiological studies. Can J Physiol Pharmacol 1990; 68: 34-9. [Crossref]

37. Perreault CL, Shannon RP, Komamura K, Vatner SF, Morgan JP. Abnormalities in intracellular calcium regulation and contractile function in myocardium from dogs with pacing-induced heart failure. J Clin Invest 1992; 89: 932-8. [Crossref]

38. Marzo KP, Frey MJ, Wilson JR, Liang BT, Manning DR, Lanoce V, et al. Beta-adrenergic receptor-G protein-adenylate cyclase complex in experimental canine congestive heart failure produced by rapid ventricular pacing. Circ Res 1991; 69: 1546-56. [Crossref]

39. Howard RJ, Stopps TP, Moe GW, Gotlieb A, Armstrong PW. Recovery from heart failure: structural and functional analysis in a canine model. Can J Physiol Pharmacol 1988; 66: 1505-12. [Crossref]

40. Rabbani LE, Wang PJ, Couper GL, Friedman PL. Time course of improvement in ventricular function after ablation of incessant automatic atrial tachycardia. Am Heart J 1991; 121: 816-9. [Crossref]

41. Steinhoff JP, Sheahan RG. Tachycardia-induced cardiomyopathy: atrial fibrillation and congestive heart failure. Am J Med Sci 2005; 329: 25-8. [Crossref] 